\title{
Curing behaviour of unsaturated polyester resin and interfacial shear stress of sugar palm fibre
}

\author{
N. Mohd Nurazzi ${ }^{1}$, A. Khalina ${ }^{1,2 *}$, S. M. Sapuan ${ }^{1,2}$, A. M. Dayang Laila ${ }^{1}$ and \\ M. Rahmah ${ }^{3}$ \\ ${ }^{1}$ Faculty of Engineering, Universiti Putra Malaysia, 43400 UPM Serdang, Selangor, \\ Malaysia \\ ${ }^{2}$ Institute of Tropical Forestry and Forest Products (INTROP), Universiti Putra \\ Malaysia, 43400 UPM Serdang, Selangor, Malaysia \\ ${ }^{3}$ Faculty of Applied Sciences, Universiti Teknologi MARA (UiTM), \\ 40450 Shah Alam, Selangor, Malaysia \\ * Email: khalina.upm@gmail.com \\ Phone: +60389466420
}

\begin{abstract}
Studies on the effect of cobalt of unsaturated polyester resin and the effect of treated sugar palm fibre with sodium hydroxide on single fibre strength and interfacial shear strength (IFSS) are presented in this paper. $1 \%$ of methyl ethyl ketone peroxide was used as the initiator, while cobalt of variable percentages $(0.05 \%, 0.1 \%, 0.2 \%, 0.4 \%, 0.6 \%, 0.8 \%$ and $1 \%$ ) was used as the hardener. The effects on glass transition and exothermic reaction of unsaturated polyester were studied for post curing temperature determination using differential scanning calorimetry by heating the samples at $10^{\circ} \mathrm{C} / \mathrm{min}$ heating rate from $30^{\circ} \mathrm{C}$ to $120^{\circ} \mathrm{C}$ with flowing of purge nitrogen gas atmosphere. For the single fibre test and IFSS, the treatment was carried out using sodium hydroxide solution with $1 \%$ concentration for one hour soaking time. Based on the optimisation percentage of cobalt, it was found that the higher the percentage of cobalt, the faster the sample tested to gel and cured. Treated sugar palm fibre exhibited better single fibre strength and IFSS between the matrices compared to untreated fibre due to the effectiveness of the alkali treatment. This can be attributed to the rearrangement of fibrils along the direction of tensile force and the removal of the coating layer and impurities after the alkaline treatment.
\end{abstract}

Keywords: Unsaturated polyester; sugar palm; curing characteristic; IFSS.

\section{INTRODUCTION}

Unsaturated polyester resins are an important class of high-performance engineering polymers used in numerous applications primarily in compression moulding (sheet moulding compounds), injection moulding (bulk moulding compounds), resin transfer moulding (RTM), pultrusion, filament winding and hand lay-up process [1]. 85\% of the fibre reinforced polymer (FRP) products such as boats, car and aircraft components and chairs were manufactured using polyesters [2]. To produce a composite product, the determination of gel time and curing time is a very important stage in the processing of unsaturated polyester resins. In order to achieve a good quality product, the curing reaction should occur in a controllable way [3]. Other than that, it is also important to take 
precautionary steps, especially in the estimation of mixing time; from the start of the initial mix until the resin is fully injected into the mould. This step is crucial to determine the right formulation mix of hardener required to optimise the time needed before the resin gels and hardens. This is especially vital when RTM or any other complex shape is to be employed for future application, as resin must be in working fluidic flow and unwanted fast cure must be observed in the equipment. Besides, the curing reaction is a very complicated process that is affected by many different things, such as weather, humidity, storage conditions and so on [4]. Cook et al. [5] stated that, decreasing gel time in a reciprocal fashion and increased rate of polymerisation of an unsaturated polyester resin may be due to increasing concentrations of initiator (either MEKP or acetyl acetone peroxide)

Cellulosic fibres are abundantly available in nature from a variety of plant species. Cellulose is the main component of natural fibres, however, the amount of pure cellulose, hemicellulose, pectin, lignin and other extractives will vary from fibre to fibre. Nowadays, the most prominent natural fibres applied in research and used commercially are flax, kenaf, hemp, bamboo, pineapple leaf fibre (PALF), cotton, ramie, sisal, coir, and sugar palm due to their promising fibre strength. Faruk et al. [6] listed the chemical compositions of cellulose, hemicellulose, lignin and wax content as having some common natural fibres presence. The interphase properties of the natural fibre reinforced polymer composites may exhibit very different mechanical performance and environmental ageing resistance. The interphase of fibre is a major consideration to facilitate the transfer of stress from fibre to fibre across the matric $[7,8]$. Since there is a limitation of interface issue between the natural fibres (hydrophilic) and the polymer matric (hydrophobic), the interfacial bonding and interaction between the reinforcing fibres and the resin have become important elements to be considered in the manufacturing of composites $[9,10]$. As an alternative, the surface modification of the fibres by chemical treatment has become one of the main interests of researchers nowadays. Instead of listing alkaline treatment with sodium hydroxide $(\mathrm{NaOH})$, Sreekala et al. [11] listed the present modification methods for natural fibre such as acetylation, peroxide and permanganate, and isocyanate and acrylation treatments. These modification methods may give certain contributions either on structural, tensile strength and modulus, strength flexural and modulus and thermal properties [12-15]. The structural performance of natural fibre composites after the modification of fibres either increases or decreases, hence, the understanding and revelation of the morphology of fibre are of great importance as references [16, 17].

The adhesion between the fibre and matric is a major factor in determining the interface strength under stress. Therefore, micromechanical techniques such as fibre pullout, single fibre push out and microdroplet test are extensively used to evaluate and quantify the interfacial bonding behaviour and the IFSS [18]. However, the microdroplet testing developed by Miller et al. [19] became one of the widely used single fibre-matric interfacial bond test methods to determine by Miller et al. [19]. Hence, the IFSS properties results can be computed using Eq. (1) [20-22], where $\tau$ is the interfacial shear strength (MPa), $\mathrm{F}$ is the load at maximum stress $(\mathrm{N}), \mathrm{D}$ is the single fibre diameter in metre unit and $\mathrm{L}$ is the embedded length of droplet resin $(\mathrm{m})$.

$$
\text { Formula of IFSS, } \tau=F / \pi D L
$$

According to Kang et al. [23], the IFSS equation is only derived for differential cylindrical model which consists of a single fibre and surrounded by polymer resins. The sugar palm tree, Arenga pinnata, comes from a forest plant that can be found abundantly 
in Southeast Asian countries such as Malaysia and Indonesia. It has been the topic of many research as a reinforcement in various polymer composites either in the form of short, long, random orientation and also in other types of fibre treatments [24-38]. Bachtiar et al. [[39, 40] treated sugar palm with various concentrations of $\mathrm{NaOH}$ and different soaking times. They found that, $0.25 \mathrm{M}$ solution with one hour soaking time to be the optimised concentrations and time, respectively, for tensile strength and flexural modulus, while $0.5 \mathrm{M}$ solution with four hours soaking time to be the optimised concentrations and time, respectively, for tensile modulus and flexural modulus. In this paper, studies on the gel and curing behaviours of unsaturated polyester using different percentages of cobalt as hardener were conducted. The structural analysis of untreated and treated sugar palm fibres, the strength of the single fibre and IFSS of sugar palm fibre embedded with unsaturated polyester resin were also investigated.

\section{METHODS AND MATERIALS}

\section{Materials}

The sugar palm fibre was obtained from Kampung Kuala Jempol, Negeri Sembilan, Malaysia. The unsaturated polyester resin (UPE)(RTM grad-40\% of styrene content, density of $1.025 \mathrm{~g} / \mathrm{cm}^{3}$ ), methyl ethyl ketone peroxide (MEKP) (Butanox-M50) as an initiator and cobaltnapthanate as an accelerator, Cobaltnapthanate is a product of CCP Composites Resins Malaysia Sdn. Bhd., while $\mathrm{NaOH}$ is by MERCK (M) Sdn. Bhd. Sodium hydroxide $(\mathrm{NaOH})$ pallets was supplied by MERCK (M) Sdn. Bhd.
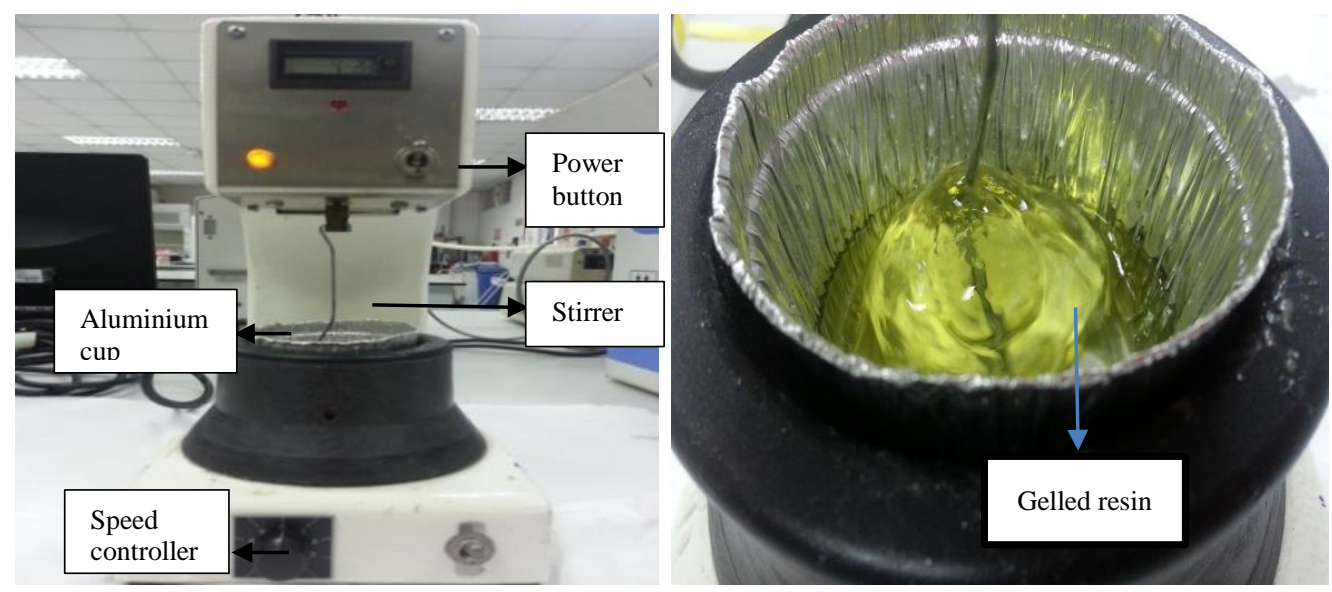

(a)

(b)

Figure 1. (a) Gel timer machine, and (b) UPE starts to gel after a certain processing time.

\section{Treatment of Sugar Palm Fibre}

The fibres were soaked in $1 \% / 0.25 \mathrm{M}$ of sodium hydroxide $(\mathrm{NaOH})$ alkaline solutions for one hour. Then, the treated fibre was washed with distilled water until it reached $\mathrm{pH} 7$ and dried at a temperature of $60^{\circ} \mathrm{C}$ for 24 hours in the oven.

\section{Determination of Gel and Curing Time}

The purposes of the analysis are to get the optimum processing time and to estimate the changes of curing mixing resin with variable amount of cobalt loading and time. The gel time and curing time of UPE were investigated using a gel timer machine (Gardcomodel). 
The curing time of UPE was analysed by physical observation under room temperature. The UPE resin was mixed with a constant percentage of MEKP $(1 \%)$ and different percentages of cobalt $(0 \%, 0.05 \%, 0.1 \%, 0.2 \%, 0.3 \%, 0.4 \%, 0.6 \%, 0.8 \%$ and $1.0 \%)$. The mixed resin (UPE:MEKP:Cobalt) was stirred at a speed of $0.05 \mathrm{~ms}^{-1}$ until it turned to gel (Figure 1).

\section{Determination of Tg of Unsaturated Polyester Resin}

The glass transition $\left(\mathrm{T}_{\mathrm{g}}\right)$ and change of exothermic reaction of unsaturated polyester resins upon the addition of different percentages of cobalt was analysed using DuPont DSC 7 by Perkin Elmer. 8mg to $10 \mathrm{mg}$ of samples were weighted and crimped in an aluminium pan. The samples were heated from $30^{\circ} \mathrm{C}$ to $120^{\circ} \mathrm{C}$ at a rate of $10^{\circ} \mathrm{C} /$ with flowing of purge nitrogen gas atmosphere.

\section{FTIR Analysis of Sugar Palm Fibre}

The structural changes of sugar palm fibre were analysed using Perkin Elmer Fourier Transform Infrared (FTIR) spectrometer. The FTIR test was run using transmission mode in the range of $4000 \mathrm{~cm}^{-1}$ to $600 \mathrm{~cm}^{-1}$ with 16 scans. The fibre particles were mixed with potassium bromide (KBr) and pressed into a small disc of about $1 \mathrm{~mm}$ thick [41].

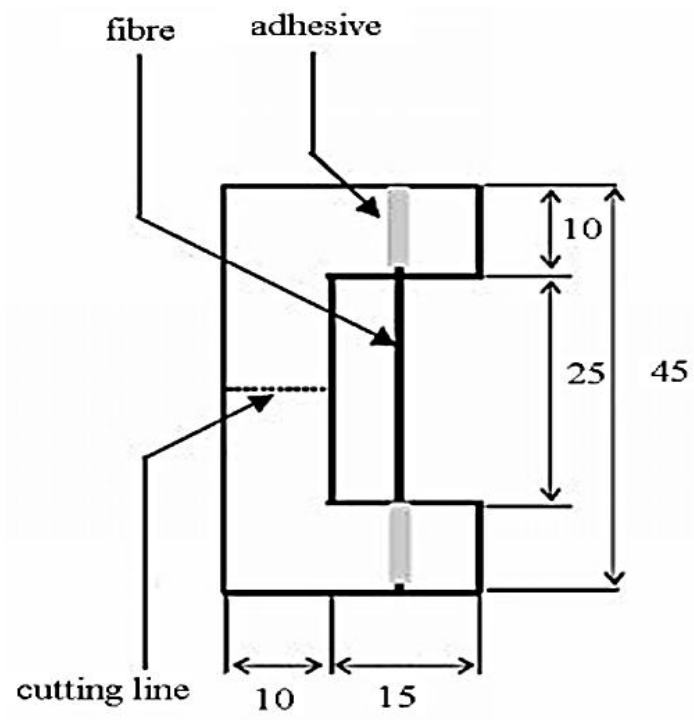

(a)

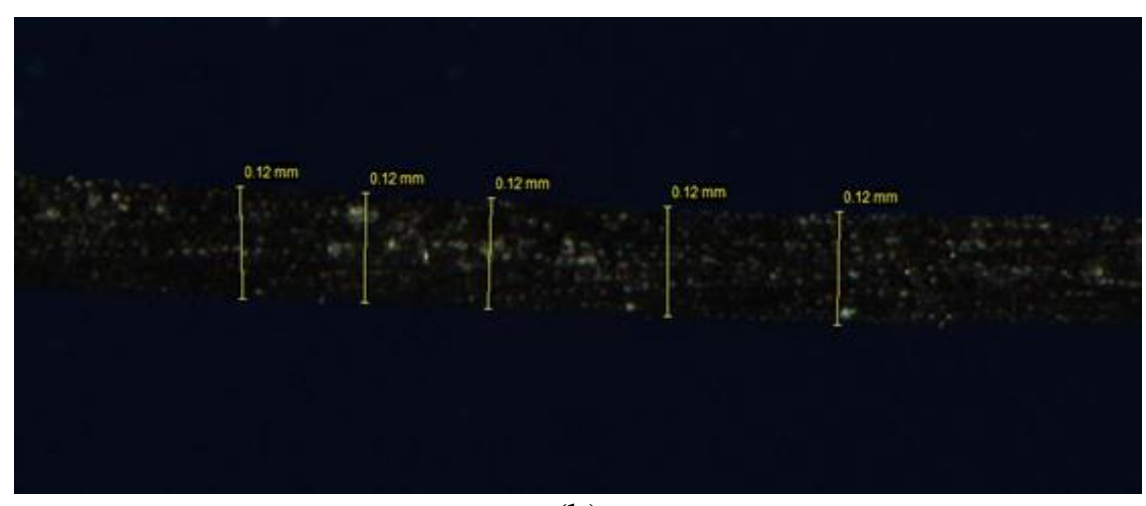

(b)

Figure 2. (a) Schematic diagram of specimens for single fibre test mounted on the cardboard [26] and (b) image of diameters measured using optical microscope. 


\section{Single Fibre Test of Sugar Palm Fibre}

A single fibre tensile test was conducted in accordance with ASTM D3379 for single fibres. Single fibres from each untreated and treated sugar palm fibres were attached to a cardboard frame as shown in Figure 2. The fibres were mounted and glued on the tab, designed with a gauge length of $20 \mathrm{~mm}$, and the diameters were measured using an optical microscope model Olympus SZX12. The specimens were tested using universal testing machine model Instron 3366 with $5 \mathrm{kN}$ load capacity with a crosshead speed of $1 \mathrm{~mm} / \mathrm{min}$. For each sample, five repetitions were performed and the average of the five tests was reported. The surface morphology of untreated and treated sugar palm fibres were examined using Polarise Optical Microscope (POM).

\section{Microdroplet test}

A microdroplet test was carried out to determine the interfacial adhesion or IFSS characteristics between untreated and treated sugar palm fibres embedded with unsaturated polyester resins. The fibres were mounted and glued on the tab which was designed with a gauge length of $20 \mathrm{~mm}$. The diameters of the single fibres (D) and embedded length of the droplets (L) were measured using an optical microscope model Olympus SZX12. The microdroplet test was done by firstly applying a resin drop onto the surface of a single fibre, curing the fibre-resin to form the droplet and then applying a shearing force to pull the fibre out of the droplet. The schematic diagram of the microdroplet test is shown in Figure 3. The analysis of IFSS was performed using Eq. (1). The specimens were then tested with $5 \mathrm{kN}$ load capacity with a cross head speed of $1 \mathrm{~mm} / \mathrm{min}$ using the universal testing machine model Instron 3366. For each sample, five repetitions were performed and the average of the five tests was reported.

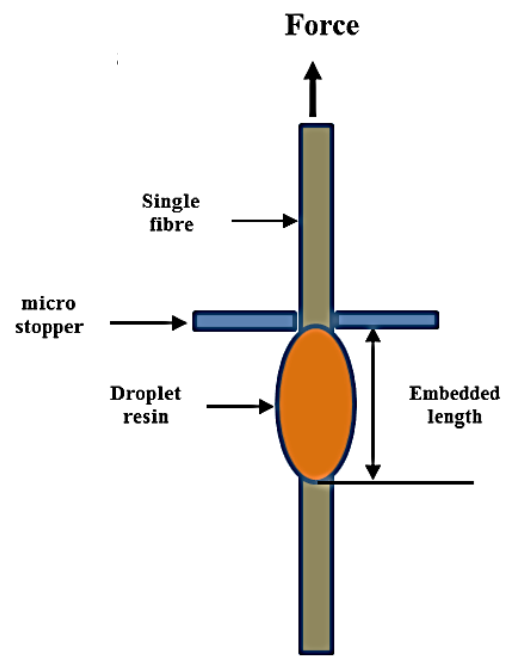

(a)

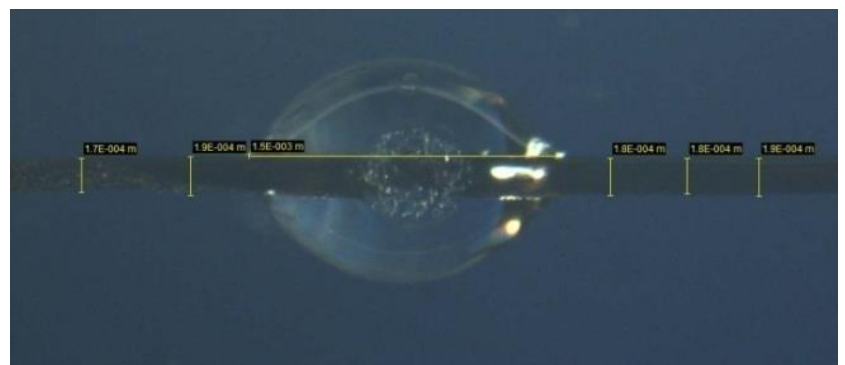

(b)

Figure 3. (a) Schematic diagram of a micro droplet [22], (b) Current studies of unsaturated polyester microdroplets adhered on a single fibre under microscope.

\section{RESULTS AND DISCUSSION}

\section{Gel Time and Curing Time Analysis}

Figure 4 shows the effect of the addition of cobalt content between $0.05 \%$ and $1 \%$ on gel time and curing time of polyester resins. A downward trend of the gel time and curing time was observed. The patent showed that as the percentage of cobalt increased, both the 
gel time and curing time decreased. Initially, without the addition of the hardener, the unsaturated polyester recorded curing time was about 50 minutes. After the addition of $0.05 \%$ of cobalt, the gel time decreased $56 \%$, which was from 50 to 32 minutes. As the MEKP became a reactive compound, the peroxide-free radical of MEKP started the polymerisation reaction by attacking the styrene that was present in the resin, which allowed the formation to cross-link with another polyester chain [42].

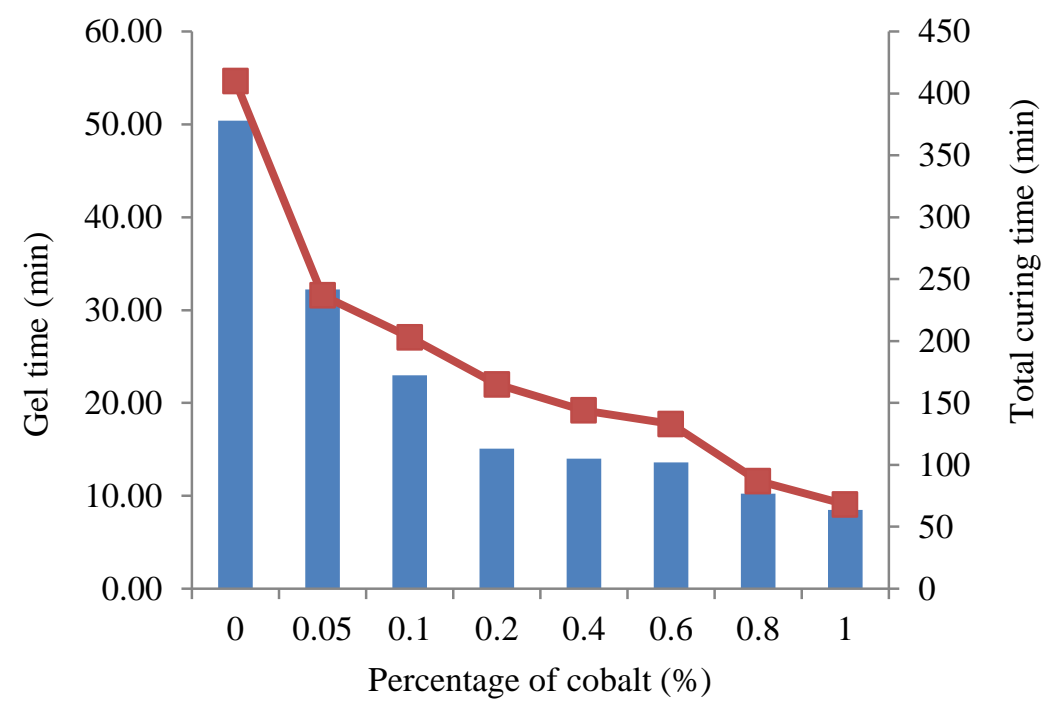

Figure 4. Effect of gel time and curing time of unsaturated polyester.

Initially, the gelation rate was determined by MEKP, which initiated polymerisation and cross-link. With the addition of cobalt as the accelerator, the polymerisation started to cross-link faster [43]. However, the effect of cobalt was limited to the increase in rate only, not the number of cross-links. The reactions occurred at room temperature, but the exothermic reaction took place upon curing. According to Bharat et al. [43], the processing temperature and the amount of catalyst can control the rate of polymerisation. The higher the temperature, or the more the catalyst, the faster the reaction will be. According to Nabil et al. [44], the processing of fabrication cost may be reduced with a shorter curing time. The determination of gelation and curing time are important in the manufacturing of composites using the RTM. Hence, sufficient processing time can be estimated starting from the mixing of UPE:MEKP:cobalt, the flowing in the tubing, as well as the time needed for the resin to penetrate into the fibre before it becomes a gel and a fully cured composite product.

\section{Glass Transition and Exothermic Reaction of Unsaturated Polyester Resin}

The glass transition ( $\mathrm{Tg}$ ) indicates material changes from glass or amorphous into a rubbery state. Table 1 and the DSC thermogram in Figure 5 show that the resin is not fully cured. A secondary heating was needed to fully cure the resin. Partially cured resin was observed with exothermic peak and glass transition of precured resin. It is clearly shown that there a few differences of $\mathrm{Tg}$ with different loadings of cobalt. The $\mathrm{Tg}$ values for all samples were identified to be around $68^{\circ} \mathrm{C}$ to $73^{\circ} \mathrm{C}$. The curing temperature was around $68^{\circ} \mathrm{C}$ to $73^{\circ} \mathrm{C}$. The lowest curing temperature was indicated by the $0.6 \%$ of cobalt (blue thermogram), while the highest was by the $0.8 \%$ of cobalt (red thermogram). The uncured or partially cured resin was observed with exothermic enthalpies. The highest 
exothermic was observed on the control sample (without cobalt) with the highest enthalpy value of $2.39 \mathrm{~J} / \mathrm{g}$. The high amount of exothermic corresponded to the greater amount of uncured resin.

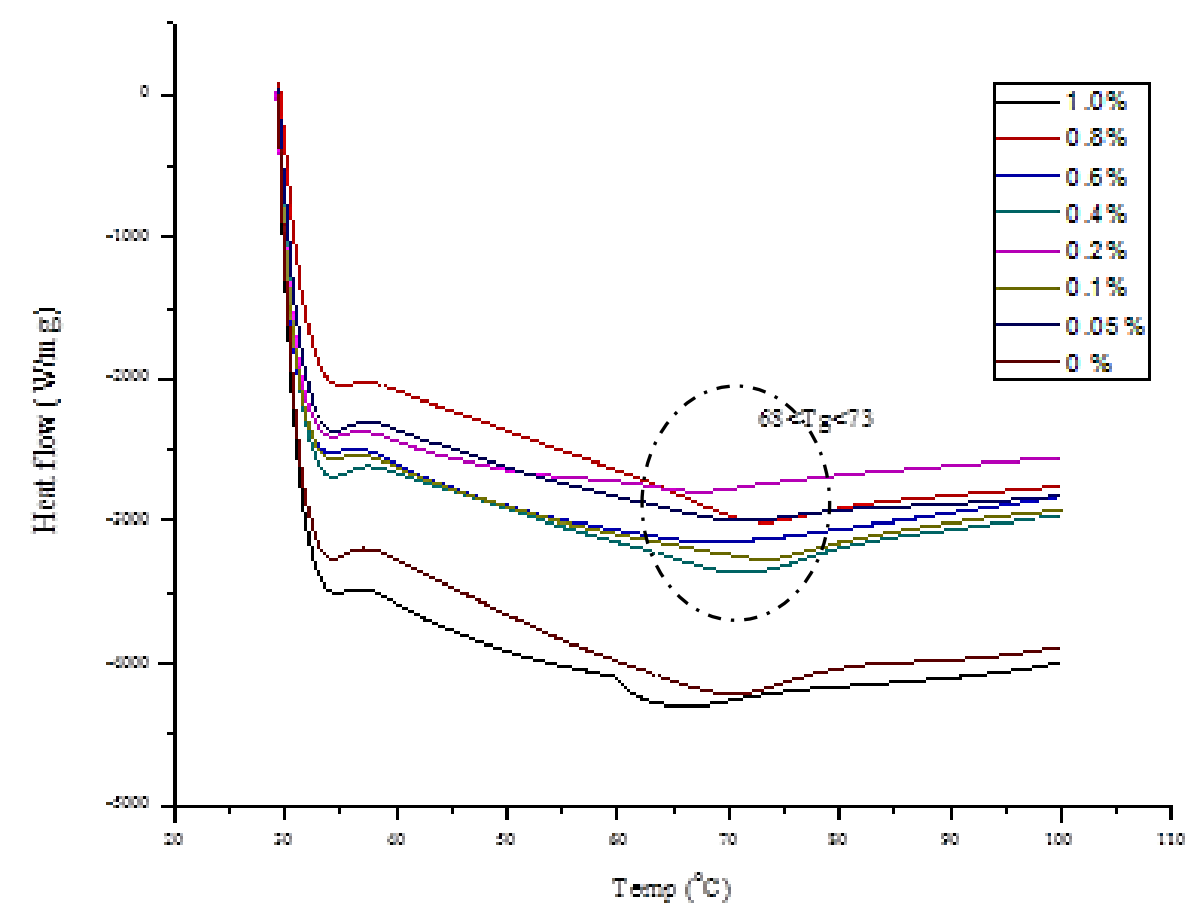

Figure 5. Glass transition analysis with different percentages of hardener.

Table 1. Effect of total curing time ( $\mathrm{min}$ ) on Tg with different percentages of cobalt.

\begin{tabular}{lcccccccc}
\hline \multicolumn{8}{c}{ Samples } \\
\hline Cobalt $(\%)$ & 0 & 0.05 & 0.1 & 0.2 & 0.4 & 0.6 & 0.8 & 1.0 \\
Tg $\left({ }^{\circ} \mathrm{C}\right)$ & 70.2 & 71.3 & 72.9 & 73.1 & 72 & 68.8 & 73.4 & 71.8 \\
Total curing & & & & & & & & \\
time (min) & 410 & 237 & 203 & 165 & 144 & 133 & 87 & 68 \\
\hline
\end{tabular}

The rigidity of network UPE upon cross-linking was similar to the initiation site of cross-linking provided by the MEKP, which cross-linked with styrenic groups and unsaturated vinyl UPE. The addition of hardener did not affect the cross-link density of UPE; it only fastened the resin's gel time and curing time. The $\mathrm{Tg}$ values varied slightly around $\sim 4^{\circ} \mathrm{C}$ for lowest $\mathrm{Tg}$ with $0.06 \%$ of cobalt and highest Tg with $0.02 \%$ of cobalt as shown in Table 1 . The slight changes on some of the Tg values upon the addition of cobalt may be due to the decrease of mobility of the chains and the inability of the initiator to form a regular cross-linking network [45]. Therefore, from the results of the exothermic reaction and the formation of an unstable cross-linking which was still in the pre-cure stage, full curing was required for a complete cure. Hence, post-curing of the sample was done within the temperature of between $70^{\circ} \mathrm{C}$ to $80^{\circ} \mathrm{C}$ for at least 90 minutes instead of curing under room temperature, as previously done by Varma et al. [46]. In order for a complete cure to take place, the internal morphology and the cross-linked reaction of the UPE have to reach $99 \%$ or $100 \%$ for the UPE resin to transform from a rubbery state to an amorphous state. 


\section{Structural and Morphology Analysis of Sugar Palm Fibre}

Figure 6 shows the FTIR spectra of chemical changes in sugar palm fibre before and after the treatment. It is well known that natural fibre mainly consists of cellulose, hemicellulose and lignin. Hemicellulose is composed of different sugars and other various substituents which are water soluble because it is easy to hydrolyse. Then, a part of lignin is soluble in alkali solution. Therefore, it was possible that a part of hemicellulose and lignin were dissolved and decreased during the alkali solution treatment [47]. The trend showed the changes, which were almost the same for the sugar palm fibre, before and after the treatment. The difference was only found in the slight shifting of the wave numbers. Firstly, the vibration peak, which was around $1760 \mathrm{~cm}^{-1}$ to $1665 \mathrm{~cm}^{-1}$ associated with carbonyl $(\mathrm{C}=\mathrm{O})$ groups of hemicellulose, was not clearly present even in the untreated sugar palm fibre. This may be due to a relatively low hemicellulose content in the sugar palm ranging between $4.71 \%$ to $7.93 \%$ [48, 49].

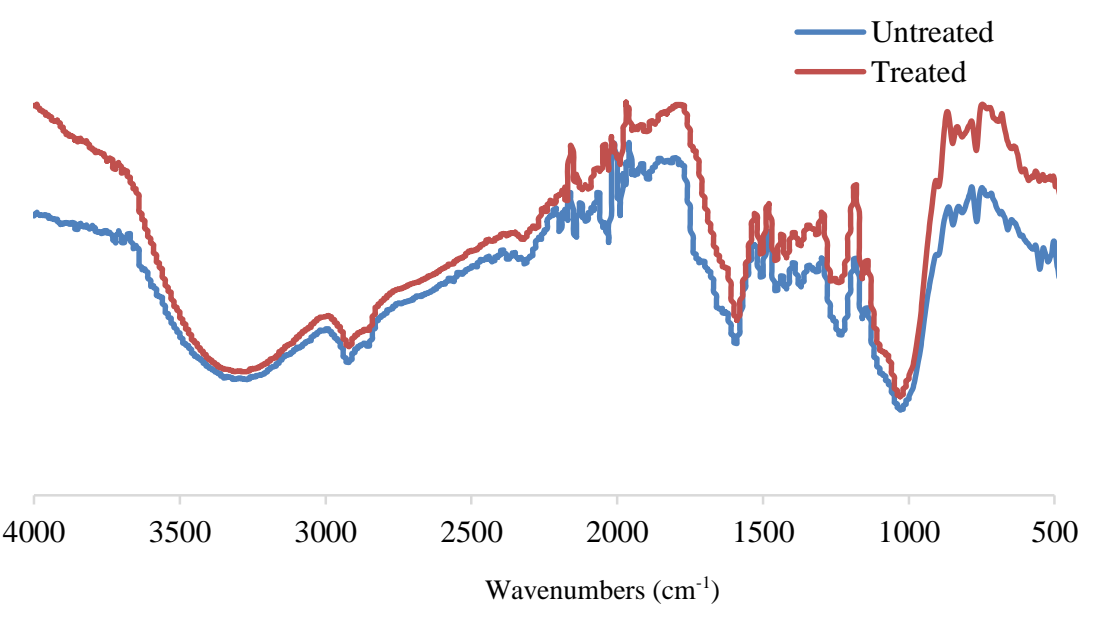

Figure 6. FTIR spectra of untreated and treated sugar palm fibres with $1 \% \mathrm{NaOH}$.

The peak intensity reduction found at around $1230 \mathrm{~cm}^{-1}(\mathrm{C}-\mathrm{O})$ of the acetyl group in lignin component for $1 \%$ and $2 \%$ of treated sugar palm fibre was associated with the mercerisation of lignocellulosic fibres [50]. Mercerisation removed the waxy layer, adhesive pectins and hemicelluloses that bind the fibre bundles to each other and to the pectin and hemicellulose rich sheats of the core [41]. The vibration peak at around $1580 \mathrm{~cm}^{-1}$ to $1590 \mathrm{~cm}^{-1}$ (C-C) associated with the benzene ring of lignin reduced as the alkali treated concentration increased. In addition, the vibration peak of $\mathrm{C}-\mathrm{H}$ stretched at $2900 \mathrm{~cm}^{-1}$ in cellulose and hemicellulose that was present in the untreated fibre became weak, indicating that the part of the hemicellulose was removed [47]. Besides cleaning and modifying the fibre surface, alkali treatment reduces the hydrogen bonding due to the removal of the hydroxyl groups $(-\mathrm{OH})$ by reacting with sodium hydroxide $[51,52]$. The hydroxyl groups are also involved in hydrogen bonding with the carboxyl groups, perhaps also with the fatty acids that are available on the fibre surface of sugar palm fibres. Thus, for this test, it was indicated by the reduction and broadening of the peaks around $3200 \mathrm{~cm}^{-}$ ${ }^{1}$. Figure 7 shows a typical reaction of sodium hydroxide with a natural fibre [53].

$$
\text { Fibre- } \mathrm{OH}+\mathrm{NaOH} \longrightarrow \text { Fibre- } \mathrm{O}^{-} \mathrm{Na}^{+}+\mathrm{H}_{2} \mathrm{O}+\text { surface impurities }
$$

Figure 7. Chemical reaction of natural fibre with $\mathrm{NaOH}$ solution. 
Figure 8 shows the morphological surface of sugar palm fibre before and after it was soaked in $1 \%$ of $\mathrm{NaOH}$ for one hour. Based on observations of its microstructure, there was a strong evidence that $\mathrm{NaOH}$ treatment changed the physical surface appearance of the sugar palm fibre compared to the untreated sugar palm fibre. It showed that the physical changes with slight fibrillation can be clearly observed on the outer surface of the fibre and it was due to the removal of the waxy layer on the outer surface (Figure 8(b)).

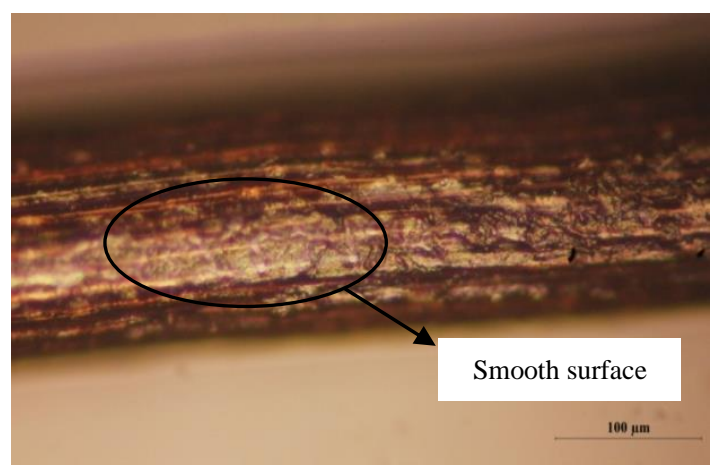

(a)

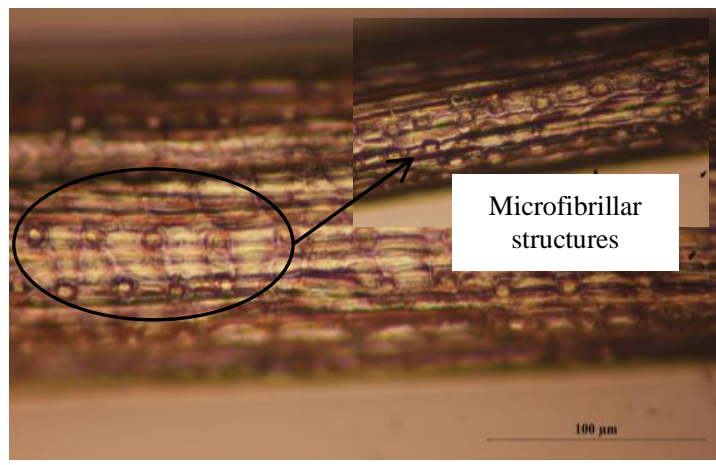

(b)

Figure 8. (a) Surface morphology of untreated and (b) treated sugar palm fibres.

Moreover, the alkali treatment may lead to fibre fibrillation, which is the breaking down of fibre bundles into smaller fibres, that increases the effective surface available for contact with the matric. This resulted in the single fibre and IFSS properties embedded with polyester resin to increased tremendously after the treatment. This was also thought to be caused by the treated sugar palm fibres having good interfacial bonding with the matric, therefore, resulting in a larger mechanical interlocking force between the fibre and the matric $[54,55]$.

\section{Single Fibre Strength of Sugar Palm Fibre}

Table 2 shows the comparison of tensile strength, modulus and elongation of untreated $1 \%$ treated sugar palm fibre with some other fibres. It was reported by Bachtiar et al. [23], that the treated sugar palm reinforced epoxy composite using $1 \%$ or $0.25 \mathrm{M}$ of $\mathrm{NaOH}$ concentration, with one hour soaking time showed higher tensile strength compared to four hours and eight hours of soaking time [39]. The tensile strength of treated sugar palm fibre was approximately $110 \%$ greater compared to the value of untreated sugar palm fibre. This increase can be attributed to the removal of lignin and hemicellulose, which facilitated the rearrangement of fibrils along the direction of tensile deformation, hence caused higher tensile strength [56, 57].

In comparing the performance of sugar palm with other fibres on Table 2, the tensile strength of sugar palm showed moderate value and was almost similar with the strength of bamboo, kenaf and coir within the range of between 140MPa to $215.4 \mathrm{MPa}$. On the other hand, the tensile strength of the treated sugar palm fibre was $332.28 \mathrm{MPa}$, which was higher than bagasse, bamboo, kenaf and coir fibres and was almost similar to flax and jute. It means that there is a potential of using sugar palm fibres as reinforcement to polymer composites research and applications. The tensile modulus of treated sugar palm fibre increased from 4.96GPa to $17.27 \mathrm{GPa}$. The improvement of modulus may indicate an improvement in the crystallinity index of cellulose due to the removal of the hemicellulose and lignin content, leading to better packing of cellulose chains, and therefore, causing a decrease in the spiral angle and an increase in the degree of molecular 
orientation. In other words, the fibres become relatively ductile after the removal of some hemicellulose and lignin content which results in the improvement of stiffness due to the increase in crystallinity of hard cellulose $[58,59]$.

Table 2. Comparison of mechanical properties of untreated and $1 \%$ treated sugar palm with other fibres [60-63].

\begin{tabular}{lcccc}
\hline Fibres & $\begin{array}{c}\text { Density } \\
\left(\mathrm{g} / \mathrm{cm}^{3}\right)\end{array}$ & $\begin{array}{l}\text { Tensile strength } \\
(\mathrm{MPa})\end{array}$ & $\begin{array}{c}\text { Elongation at } \\
\text { break }(\%)\end{array}$ & $\begin{array}{c}\text { Tensile Modulus } \\
(\mathrm{GPa})\end{array}$ \\
\hline Sugar Palm & 1.292 & 156.96 & 7.98 & 4.96 \\
Treated sugar palm & 1.193 & 332.28 & 5.3 & 17.27 \\
$(1 \% \mathrm{NaOH})^{*}$ & & & & \\
Bagasse & 1.5 & 290 & - & 17 \\
Bamboo & 1.25 & $140-230$ & - & $11-17$ \\
Flax & $0.6-1.1$ & $345-1035$ & $2.7-3.2$ & 27.6 \\
Hemp & 1.48 & 690 & $1.6-4$ & 70 \\
Jute & 1.3 & $393-773$ & $1.5-1.8$ & 26.5 \\
Kenaf & 1.45 & 215.4 & 1.6 & 53 \\
Sisal & 1.5 & $511-535$ & $2.0-2.5$ & $9.4-22$ \\
Ramie & 1.5 & 560 & $2.5-3.8$ & 24.5 \\
Pineapple & $0.8-1.6$ & $400-627$ & 14.5 & 1.44 \\
Coir & 1.2 & 138.7 & 30 & $4-6$ \\
E-Glass & 2.5 & $2000-3500$ & 0.5 & 70 \\
S-Glass & 2.5 & 4570 & 2.8 & 86 \\
Aramid & 1.4 & $3000-3150$ & $3.3-3.7$ & $63.0-67.0$ \\
\hline Note: & & & &
\end{tabular}

Note: * indicates the current study done by researcher.

\section{Interfacial Shear Strength (IFSS) of Sugar Palm Fibre with Unsaturated Polyester Resin}

Figure 9 demonstrates the effect of alkaline treatment on the IFSS of sugar palm fibre. The IFSS showed an increase after the $1 \%$ alkaline treatment (from $2.59 \mathrm{MPa}$ to 3.58 MPa). Recently published studies done by [64-67] showed that the chemical treatments may enhance the mechanical properties of the treated fibres as compared to the untreated fibres. The increase in the IFSS of the treated single fibre compared to the untreated fibre was attributed to the removal of impurities and waxy substances from the fibre surface and the creation of a rougher surface after the modification. Alkali treatment cleaned the fibres' surface from impurities, which in turn increased the disruption of the moisture absorption process by removing the coating of the -OH groups in the fibre, thus, increased interface quality. Conclusively, the waxy layer contributes towards ineffective fibre matric bonding and poor surface wet out. The enhancement in the IFSS of the treated sugar palm fibre after $\mathrm{NaOH}$ treatment in the studies may be attributed to the phenomenon called fibrillation. Untreated fibres are packed together in a bundle. After the fibre treatment, the packed alignments of the fibres are broken into smaller ones through the dissolution of hemicellulose. This phenomenon increases the effectiveness of the surface area available for contact and matric penetration inside the fibre cell, thus improving interfacial adhesion [68, 69]. However, Bachtiar et al. [39] reported that tensile strength is expected to improve when the alkali concentration is raised, but from the experiment, high concentration after $0.25 \mathrm{M}$ of $\mathrm{NaOH}$ may decrease the strength due to fibre structure damage and consequently reduce the tensile strength of the fibre [39]. 


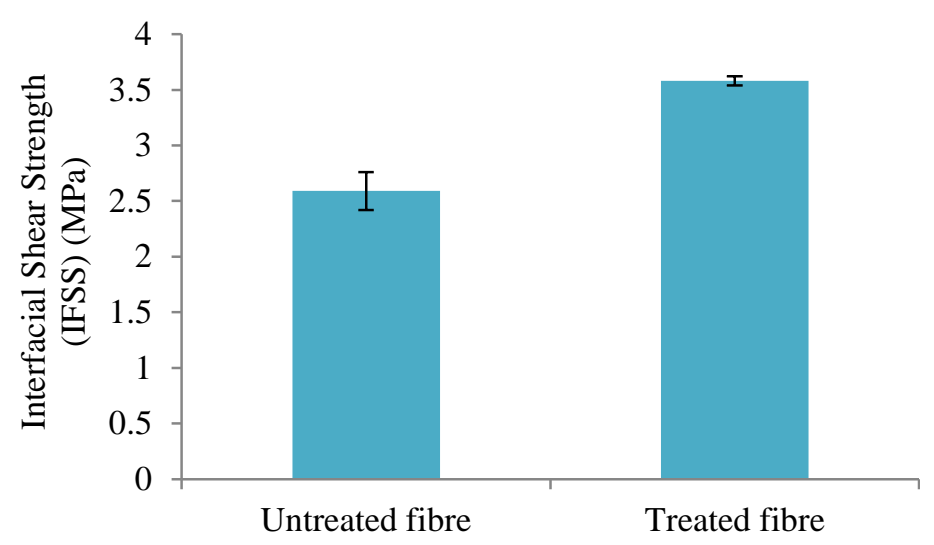

Figure 9. IFFS of untreated and treated sugar palm fibres.

\section{CONCLUSIONS}

In conclusion, other than using the MEKP as the initiator, cobalt as the hardener did assist in the formation of the crosslinking process as the curing time proportionally increased with the increase in the amount of hardener. Cure time was halved when $0.02 \%$ of cobalt solution was used. It was observed that the Tg varied slightly around $\sim 4^{\circ} \mathrm{C}$ which revealed that the cross-linked structure density and resin rigidity were not structurally affected as shown by the DSC thermogram. Post curing of unsaturated polyester was needed to complete the crosslinking formation even after 24 hours of curing time under room temperature, as a result of high exothermic peaks for some compositions of the hardener. The differences in structural features were found to be affected by the treated and untreated sugar palm fibres. Alkali treatment using $\mathrm{NaOH}$ led to the enhancement in IFSS due to internal morphological changes of sugar palm fibres.

\section{ACKNOWLEDGEMENTS}

The authors wish to thank Universiti Putra Malaysia (UPM), for providing research grants (GP-IPB), project number GP-IPB/2014/9441502 and excellent facilities. Thanks also to Faculty of Applied Sciences (FSG), Universiti Teknologi MARA (UiTM) Shah Alam for excellent facilities and cooperation.

\section{REFERENCES}

[1] Vilas JL, Laza JM, Garay MT, Rodriguez M, Leon LM. Unsaturated polyester resins cure: Kinetic, rheologic, and mechanical dynamical analysis. II. The glass transition in the mechanical dynamical spectrum of polyester networks. Journal of Polymer Science Part B: Polymer Physics. 2001;39:146-52.

[2] Devi LU, Bhagawan SS, Thomas S. Mechanical properties of pineapple leaf fiberreinforced polyester composites. Journal of Applied Polymer Science. 1997;64:1739-48.

[3] Salar B. Fibre reinforced polyester composites. Edited by Hosam El-Din M Saleh. 2012:167.

[4] Strong AB. Fundamentals of composites manufacturing: materials, methods and applications: Society of Manufacturing Engineers; 2008. 
[5] Cook WD, Lau M, Mehrabi M, Dean K, Zipper M. Control of gel time and exotherm behaviour during cure of unsaturated polyester resins. Polymer International. 2001;50:129-34.

[6] Faruk O, Bledzki AK, Fink HP, Sain M. Biocomposites reinforced with natural fibers: 2000-2010. Progress in Polymer Science. 2012;37:1552-96.

[7] Bisanda ETN. The Effect of Alkali Treatment on the Adhesion Characteristics of Sisal Fibres. Applied Composite Materials. 2000;7:331-9.

[8] Mohd Nurazzi N, Khalina A, Sapuan SM, Dayang Laila AHAM, Rahmah M, Hanafee Z. A Review: Fibres, Polymer Matrices and Composites. Pertanika Journal of Science and Technology. 2017;25:1085-102.

[9] Islam MR, Beg MDH. Effects of reinforcing arrangement of kenaf fibres into unsaturated polyester for improved properties. Journal of Mechanical Engineering and Sciences. 2016;10: 2020-30.

[10] Haque MM, Hasan M. Mechanical properties of betel nut and glass fibre reinforced hybrid polyethylene composites. International Journal of Automotive and Mechanical Engineering. 2016;13:3763-72.

[11] Sreekala MS, Kumaran MG, Joseph S, Jacob M, Thomas S. Oil Palm fibre reinforced phenol formaldehyde composites: influence of fibre surface modifications on the mechanical performance. Applied Composite Materials. 2000;7:295-329.

[12] Sgriccia N, Hawley MC, Misra M. Characterization of natural fiber surfaces and natural fiber composites. Composites Part A: Applied Science and Manufacturing. 2008;39:1632-7.

[13] Sreekala MS, Kumaran MG, Joseph S, Jacob M, Thomas S. Oil palm fibre reinforced phenol formaldehyde composites: Influence of fibre surface modifications on the mechanical performance. Applied Composite Materials. 2000;7:295-329.

[14] Uhlmann E, Piltz S, Oberschmidt D. Machining of micro rotational parts by wire electrical discharge grinding. Production Engineering Research Development. 2008;2:227 - 33 .

[15] A. MHJ, Abdul Majid MS, Afendi M, M. H, Fahmi I. Alkaline treatment and thermal properties of Napier grass fibres. International Journal of Automotive and Mechanical Engineering. 2016;13: 3238-47.

[16] Nair KC, Diwan SM, Thomas S. Tensile properties of short sisal fiber reinforced polystyrene composites. Journal of Applied Polymer Science. 1996;60:1483-97.

[17] Rokbi M, Osmani H, Imad A, Benseddiq N. Effect of Chemical treatment on Flexure Properties of Natural Fiber-reinforced Polyester Composite. Procedia Engineering. 2011;10:2092-7.

[18] Jacob M, Joseph S, Pothan LA, Thomas S. A study of advances in characterization of interfaces and fiber surfaces in lignocellulosic fiber-reinforced composites. Composite Interfaces. 2005;12:95-124.

[19] Miller B, Muri P, Rebenfeld L. A microbond method for determination of the shear strength of a fiber/resin interface. Composites Science and Technology. 1987;28:17-32.

[20] Chao ST, Bin S, Li ZZ. Interfacial shear strength of fiber reinforced soil. Geotextiles and Geomembranes. 2010;28:54-62.

[21] Joseph S. A comparison of the mechanical properties of phenol formaldehyde composites reinforced with banana fibres and glass fibres. Composites Science and Technology. 2002;62:1857-68. 
[22] Subramani SG, S. Fiber-Matrix Interface Characterization through the Microbond Test. International Journal of Aeronautical and Space Sciences. 2012;13:282-95.

[23] Kang S, Lee D, Choi N. Fiber/epoxy interfacial shear strength measured by the microdroplet test. Composites Science and Technology. 2009;69:245-51.

[24] Bachtiar D, Sapuan SM, Ahmad MMHM, Sastra HY. Chemical composition of ijuk (Arenga Pinnata) fibre as reinforcement for polymer matrix composites. Jurnal Teknologi Terpakai. 2006;4:1 - 7

[25] Bachtiar D, Sapuan SM, Hamdan MM. The influence of alkaline surface fibre treatment on the impact properties of sugar palm fibre-reinforced epoxy composites. Polymer-Plastics Technology and Engineering. 2009;48:379-83.

[26] Bachtiar D, Sapuan SM, Zainudin ES, Khalina A, Dahlan KZM. The tensile properties of single sugar palm (Arenga pinnata) fibre. IOP Conference Series: Materials Science and Engineering: IOP Publishing; 2010. p. 012012.

[27] Sapuan SM, Bachtiar D. Mechanical Properties of sugar palm fibre reinforced high impact polystyrene composites. Procedia Chemistry. 2012;4:101-6.

[28] Ishak MR, Leman Z, Sapuan SM, Rahman MZA, Anwar UMK. Effects of impregnation pressure on physical and tensile properties of impregnated sugar palm (Arengga Pinnata) fibres. Key Engineering Materials. 2011;471-472:11538.

[29] Ishak MR, Leman Z, Sapuan SM, Rahman MZA, Anwar UMK. Effects on impregnation time on physical and tensile properties of impregnated sugar palm (Arengga Pinnata) fibres. Key Engineering Materials. 2011;471-472:1147-52.

[30] Misri S, Leman Z, Sapuan SM, Ishak MR. Mechanical properties and fabrication of small boat using woven glass/sugar palm fibres reinforced unsaturated polyester hybrid composite. IOP Conference Series: Materials Science and Engineering: IOP Publishing; 2010. p. 012015.

[31] Nadlene R, Sapuan SM, Jawaid M, Ishak MR, Yusriah L. The effects of chemical treatment on the structural and thermal, physical, and mechanical and morphological properties of roselle fiber-reinforced vinyl ester composites. Polymer Composites. 2016:n/a-n/a.

[32] Sapuan SM, Lok HY, Ishak MR, Misri S. Mechanical properties of hybrid glass/sugar palm fibre reinforced unsaturated polyester composites. Chinese Journal of Polymer Science. 2013;31:1394-403.

[33] Sahari J, Sapuan SM, Ismarrubie ZN, Rahman MZA. Comparative study of physical properties based on different parts of sugar palm fibre reinforced unsaturated polyester composites. Key Engineering Materials. 2011;471472:455-60.

[34] Sahari J, Sapuan SM, Ismarrubie ZN, Rahman MZA. Physical and chemical properties of different morphological parts of sugar palm fibres. Fibres \& Textiles in Eastern Europe. 2012;20:21-4.

[35] Sahari J, Sapuan SM, Ismarrubie ZN, Rahman MZA. Tensile and impact properties of different morphological parts of sugar palm fibre-reinforced unsaturated polyester composites. Polymers \& Polymer Composites. 2012;20:861-6.

[36] Sahari J, Sapuan SM, Zainudin ES, Maleque MA. A New Approach to Use Arenga Pinnata as Sustainable Biopolymer: Effects of Plasticizers on Physical Properties. Procedia Chemistry. 2012;4:254-9. 
[37] Sahari J, Sapuan SM, Zainudin ES, Maleque MA. Thermo-mechanical behaviors of thermoplastic starch derived from sugar palm tree (Arenga pinnata). Carbohydrate Polymers. 2013;92:1711-6.

[38] Sahari J, Sapuan SM, Zainudin ES, Maleque MA. Mechanical and thermal properties of environmentally friendly composites derived from sugar palm tree. Materials \& Design. 2013;49:285-9.

[39] Bachtiar D, Sapuan SM, Hamdan MM. The effect of alkaline treatment on tensile properties of sugar palm fibre reinforced epoxy composites. Materials \& Design. 2008;29:1285-90.

[40] Bachtiar D, Sapuan SM, Hamdan MM. Flexural properties of alkaline treated sugar palm fibre reinforced epoxy composites. International Journal of Automotive and Mechanical Engineering. 2010;1:79-90.

[41] Mwaikambo LY, Ansell MP. Chemical modification of hemp, sisal, jute, and kapok fibers by alkalization. Journal of Applied Polymer Science. 2002;84:222234.

[42] Osman EA, Vakhguelt A, Sbarski I, Mutasher SA. Curing behaviour and tensile properties of unsaturated polyester containing various styrene concentrations. Malaysian Polymer Journal. 2012;7 2012:46-55.

[43] Bharat D. Unsaturated Polyester Resin for Specialty Applications 2012.

[44] Nabil FL, Zaidon A, Jawaid M, Anwar UMK, Bakar ES, Paridah MT, et al. Physical and morphological properties of nanoclay in low molecular weight phenol formaldehyde resin by ultrasonication. International Journal of Adhesion and Adhesives. 2015;62:124-9.

[45] Pothan LA, Oommen Z, Thomas S. Dynamic mechanical analysis of banana fiber reinforced polyester composites. Composites Science and Technology. 2003;63:283-93.

[46] Varma IK, Anantha Krishnan SR, Krishnamoorthy S. Composites of glass/modified jute fabric and unsaturated polyester resin. Composites. 1989;20:383-8.

[47] Liu W, Mohanty AK, Askeland P, Drzal LT, Misra M. Influence of fiber surface treatment on properties of Indian grass fiber reinforced soy protein based biocomposites. Polymer. 2004;45:7589-96.

[48] Ishak MR, Sapuan SM, Leman Z, Rahman MZA, Anwar UMK. Characterization of sugar palm (Arenga pinnata) fibres. Journal of Thermal Analysis and Calorimetry. 2011;109:981-9.

[49] Merlini C, Soldi V, Barra GMO. Influence of fiber surface treatment and length on physico-chemical properties of short random banana fiber-reinforced castor oil polyurethane composites. Polymer Testing. 2011;30:833-40.

[50] Aboul-Fadl S, Zeronian S, Kamal M, Kim M, Ellison M. Effect of mercerization on the relation between single fiber mechanical properties and fine structure for different cotton species. Textile Research Journal. 1985;55:461-9.

[51] Mohammed AA, Bachtiar D, S. DJP, R. MRM. Effect of sodium hydroxide on the tensile properties of sugar palm fibre reinforced thermoplastic polyurethane composites. Journal of Mechanical Engineering and Sciences. 2016;10:1765-77.

[52] M. HJA, Abdul Majid MS, Afendi M, Haslan M, Fahmi I. Alkaline treatment and thermal properties of Napier grass fibres. International Journal of Automotive and Mechanical Engineering. 2016;13:3238-47. 
[53] Cantero G, Arbelaiz A, Llano-Ponte R, Mondragon I. Effects of fibre treatment on wettability and mechanical behaviour of flax/polypropylene composites. Composites Science and Technology. 2003;63:1247-54.

[54] Bledzki AK, Gassan J. Composites reinforced with cellulose based fibres. Progress in Polymer Science. 1999;24:221-74.

[55] Ishak MR, Sapuan SM, Leman Z, Rahman MZA, Anwar UMK, Siregar JP. Sugar palm (Arenga pinnata): Its fibres, polymers and composites. Carbohydrate Polymers. 2013;91:699-710.

[56] Gassan J, Bledzki AK. The influence of fiber-surface treatment on the mechanical properties of jute-polypropylene composites. Composites Part A: Applied Science and Manufacturing. 1997;28:1001-5.

[57] Gassan J, Bledzki AK. Possibilities for improving the mechanical properties of jute/epoxy composites by alkali treatment of fibres. Composites Science and Technology. 1999;59:1303-9.

[58] Mohanty AK, Misra M, Drzal LT. Surface modifications of natural fibers and performance of the resulting biocomposites: An overview. Composite Interfaces. 2001;8:313-43.

[59] Rong MZ, Zhang MQ, Liu Y, Yang GC, Zeng HM. The effect of fiber treatment on the mechanical properties of unidirectional sisal-reinforced epoxy composites. Composites Science and Technology. 2001;61:1437-47.

[60] Goud G, Rao RN. Effect of fibre content and alkali treatment on mechanical properties of Roystonea regia-reinforced epoxy partially biodegradable composites. Bulletin of Materials Science. 2011;34:1575-81.

[61] Kestur GS, Gregorio GCA, Fernando W. Biodegradable composites based on lignocellulosic fibers-An overview. Progress in Polymer Science. 2009;34:9821021.

[62] Koronis G, Silva A, Fontul M. Green composites: A review of adequate materials for automotive applications. Composites Part B: Engineering. 2013;44:120-7.

[63] Saba N, Tahir P, Jawaid M. A review on potentiality of nano filler/natural fiber filled polymer hybrid composites. Polymers. 2014;6:2247-73.

[64] Shalwan A, Yousif BF. In State of Art: Mechanical and tribological behaviour of polymeric composites based on natural fibres. Materials \& Design. 2013;48:1424.

[65] Reddy GV, Naidu SV, Rani TS. Impact properties of kapok based unsaturated polyester hybrid composites. Journal of Reinforced Plastics and Composites. 2008;27:1789-804.

[66] Nirmal U, Lau STW, Hashim J. Interfacial adhesion characteristics of kenaf fibres subjected to different polymer matrices and fibre treatments. Journal of Composites. 2014;2014:1-12.

[67] John M, Thomas S. Biofibres and biocomposites. Carbohydrate Polymers. 2008;71:343-64.

[68] Khan RA, Khan MA, Zaman HU, Pervin S, Khan N, Sultana S, et al. Comparative studies of mechanical and interfacial properties between jute and e-glass fiberreinforced polypropylene composites. Journal of Reinforced Plastics and Composites. 2010;29:1078-88.

[69] Vilay V, Mariatti M, Mat Taib R, Todo M. Effect of fiber surface treatment and fiber loading on the properties of bagasse fiber-reinforced unsaturated polyester composites. Composites Science and Technology. 2008;68:631-8. 